Euskal ikerketen aldizkaria | Revue d'études basques |

Revista de estudios vascos | Basque studies review

Numéro Spécial 1 | 1999

Les lettres basques au temps d'Axular (1600-1650)

\title{
Mot d'accueil et introduction
}

Jean-Baptiste Orpustan

\section{OpenEdition \\ Journals}

Édition électronique

URL : http://journals.openedition.org/lapurdum/1589

DOI : 10.4000/lapurdum.1589

ISSN : 1965-0655

Éditeur

IKER

Édition imprimée

Date de publication : 1 octobre 1999

Pagination : 7-8

ISBN : 2-84127-157-9

ISSN : $1273-3830$

\section{Référence électronique}

Jean-Baptiste Orpustan, « Mot d'accueil et introduction », Lapurdum [En ligne], Numéro Spécial 1 |

1999, mis en ligne le 01 juin 2010, consulté le 29 janvier 2020. URL : http://journals.openedition.org/ lapurdum/1589; DOI : 10.4000/lapurdum.1589 


\section{Jean-Baptiste ORPUSTAN}

\section{Mot d'accueil et introduction}

\section{Mesdames et messieurs,}

Bienvenue à ce cinquième colloque organisé à Bayonne par notre unité de recherche depuis sa création, et tous nos remerciements à la direction de cette faculté qui nous accueille ici. A ce colloque, programmé depuis quelque temps et remis pour raisons d'opportunité, et qui peut aujourd'hui se tenir ici, et à ceux qui l'ont précédé, il convient d'ajouter ceux où notre unité a été partenaire de l'Académie de la langue basque-Euskaltzaindia (Bonaparte et Dialectologie, Oyhénart, Elissamburu, Abbadie d'Arrast). Tous ces travaux sont aujourd'hui disponibles dans les Actes publiés ici ou là.

Avant d'en venir au sujet de ces deux journées, il me revient de vous informer sur l'unité et sa composition. A l'heure actuelle, étant donné qu'on ne peut statutairement appartenir qu'à une seule unité de recherche, associée au CNRS (comme la nôtre) ou non, même si des chercheurs extérieurs appartenant à d'autres unités peuvent s'associer à ses travaux, les membres de l'unité sont : Jacques Allières, Professeur émérite de Toulouse II, Aurélie Arcotxa-Scarcia, Maître de Conférences à Bordeaux III, Jean Casenave, docteur en Études Basques, Jean Haritschelhar, Professeur émérite de Bordeaux III, Michel Morvan, Docteur en Études Basques, Bernard Oyharçabal, Directeur de Recherches au CNRS, Charles Videgain Maître de Conférences à Pau et JeanBaptiste Orpustan, Professeur à Bordeaux III, Directeur de l'Unité depuis 1989 et qui cédera la direction de l'Unité à $\mathrm{M}$. Bernard Oyharçabal à partir du 2 mai prochain. Par ailleurs, et sur la volonté expresse du CNRS, notre unité "propre de recherche associée" est en passe de se transformer en UMR "Unité mixte de recherches", avec le même intitulé et le même objectif : la recherche sur la langue basque et tout ce qui s'est écrit, noté, improvisé (littérature orale incluse) en langue basque hier et aujourd'hui. La transformation en UMR suppose qu'un accord, dont le principe est déjà acquis, soit passé entre l'Université de Bordeaux III et celle de Pau et Pays de l'Adour, les seules à préparer et à délivrer des diplômes d'Études Basques : l'UMR associera ainsi officiellement le CNRS aux deux universités pour conforter et développer la recherche sur la langue basque et l'écrit basque, avec de nouveaux chercheurs docteurs en Études Basques, et en collaboration, comme l'ont fait nos travaux précédents et ce colloque lui-même, avec des chercheurs extérieurs aux deux universités.

Le sujet de ce colloque paraîtra un peu "classique" : Axular n'est-il pas le plus connu de nos auteurs et le plus universellement (mais seulement chez les connaisseurs de la littérature de langue basque...) admiré et reconnu ? Pourtant à la lecture d'un ouvrage récent (Los escritores hitos de la literatura clasica euskérica, 
Sancho el Sabio 1996), je remarque qu'on (c'est-à-dire en l'occurrence M. P. Altuna) s'interroge encore sur la date de naissance d'Axular (vers 1556, ou plus de 15 ans plus tard vers 1572 ?), sur la période de son séjour à Salamanque assez récemment découverte (années 1580 ou années 1590 ?), sur la structure même de Guero et son fameux "bi partetan partitua eta berecia" ? A plus forte raison y at-il matière à recherche et analyse autour d'Axular, chez ses nombreux contemporains, labourdins ou souletins, qui publièrent des livres en basque à son époque, la première moitié du XVII ${ }^{\circ}$ siècle pour la production la plus dense, mais qui peut aussi s'étendre du temps de Liçarrague (1571) à celui d'Arambillague (1684), sinon même d'Etcheberry de Sare (1712) qui se réclame encore tant de son maître et devancier le curé de Sare. Et puis tous les épigones, imitateurs, traducteurs, éditeurs et rééditeurs du Guero jusqu'au XIX ${ }^{\circ}$ siècle inclus ne touchent-ils pas encore à la recherche "axularienne" ?

A toutes ces questions, et quelques autres, on ne s'étonnera pas si nous n'apportons durant ces deux journées et dans la douzaine de communications présentées, que des réponses ponctuelles et partielles, sinon parfois de nouvelles questions qui demanderont elles-mêmes de nouveaux chantiers de recherche. Aux travaux portant sur la littérature et. la langue basques proprement dites, s'ajouteront quelques exposés de chercheurs d'autres disciplines sur l'environnement social, éducatif, historique, dans lequel s'inscrit l'essor de la littérature et de l'écrit en langue basque au début du XVII ${ }^{e}$ siècle, et qui a eu sur cet essor et les auteurs qui l'ont assuré, une influence déterminante et encore trop mal mesurée. Cette dimension pluridisciplinaire a été un trait constant de nos colloques, dans la mesure où le sujet s'y prêtait, et celui-ci, évidemment, l'exigeait tout particulièrement

Les communications se feront en basque ou en français, selon la volonté des auteurs, et peut-être l'opportunité du public présent, et chaque communication pourra être suivie de quelques questions dans la mesure de la disponibilité horaire.

N.B. Les communications et conférences, présentées lors du colloque selon les possibilités horaires des communicants, ont été regroupées et ordonnées par discipline pour ces Actes, conformément à la présentation habituelle des articles de notre revue $L A P U R D U M$, dont ils feront le premier "numéro spécial". De même, et suivant la règle du CNRS, toute communication qui n'est pas écrite en français est suivie d'un résumé assez substantiel en français : il s'agit, tout le monde le sait, de pouvoir communiquer les recherches et leurs résultats au public le plus large possible. 